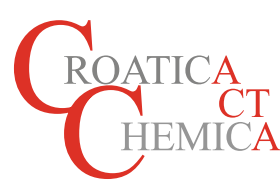

\title{
Memories of the moments spent with Edward Cameron Kirby (1934 - 2019)
}

\author{
by Sanja Tomić \\ Ruđer Bošković Institute, Zagreb, Croatia
}

$\mathbf{F}$ OR the first time I met Edward at Math/Chem/Comp (MCC) 1990 in Dubrovnik (Figure 1.). Our friendship started in Duždeva palace (Doge's Palace). All participants of the conference were invited to the concert of classical music organized there, and since we were sitting each to other we chatted during the break. Next day Edward came in front of my poster and asked me some details about the data presented. I was pleased to have somebody interested in my work since most of the presentations at the conference were about graph theory while mine was about molecular dynamics simulations, the research field that I had just started to work in.

In winter the same year Edward and his wife Jean visited me in Zagreb and spent a few days with my family. Edward again visited us in June 1991, on his way to

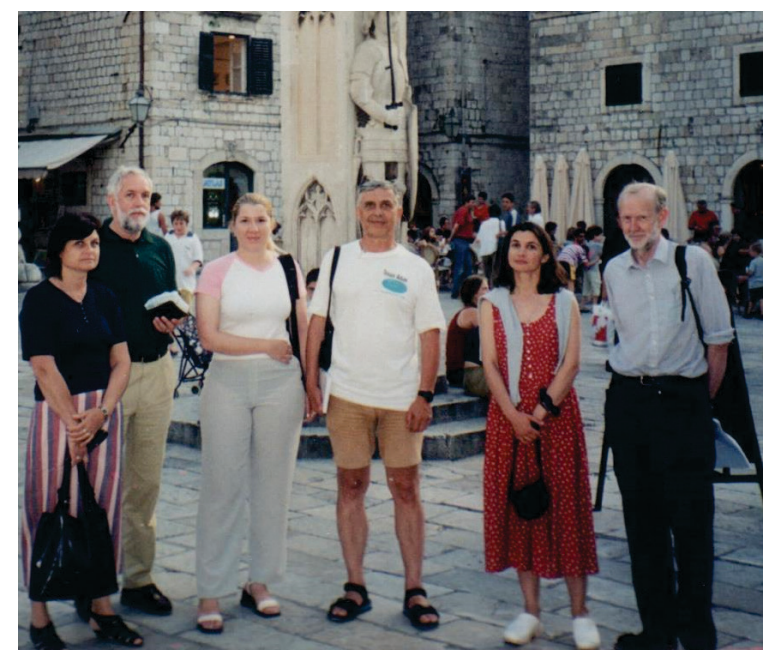

Figure 1. Some of the MCC1990 participants in front of the Orlando Column in Dubrovnik old town. Edward is the first from the right.
Dubrovnik. That time we took him to Gorski Kotar (Figure 2.). In autumn I went for a short fellowship to Utrecht. Unexpectedly, Edward visited me there and spent a Sunday afternoon with me, my daughter, my niece and my mother who were with me (Figure 2.). After that, either alone, or together with Jean, Edward has been regularly visiting us almost each year. A few times they even joined us for holidays. They would always brought a pile of presents for my daughters and Jean used to play with them, so they were always were excited when expected visit from Scotland.
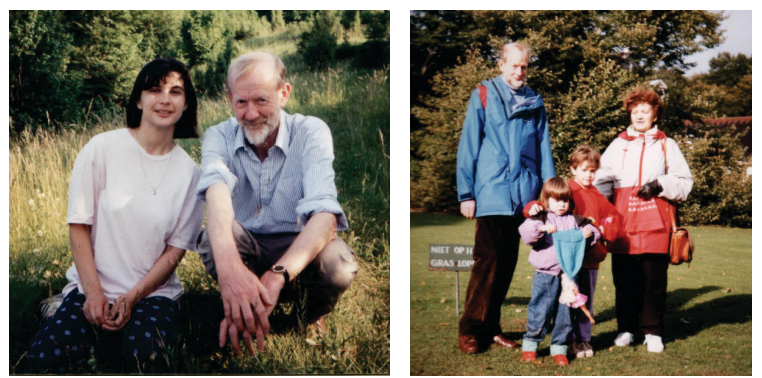

Figure 2. 1991. Left - Edward and I in Gorski kotar. Right Edward with my mother, my daughter and my niece in a place near Utrecht.

In 1996 I was awarded a Humboldt Fellowship, and the period from summer 1996 to summer 1998, I spent, together with my family, in Heidelberg. This was opportunity to finally accept the Kirby's invitation and to visit them. A few days before the end of 1997 we arrived to Edinburgh. Edward arrived by car to the airport and took us to Pitlochry where we spent New Year with him and Jean. For this occasion Edward dressed his kilt, but unfortunately I do not have a photo. Edward enjoyed taking photos of all of us, so we have a lot of memories on their visits, but unfortunately Edward is only on few of them.

(cc) $\mathbf{B Y}$ This work is licensed under a Creative Commons Attribution 4.0 International License. 

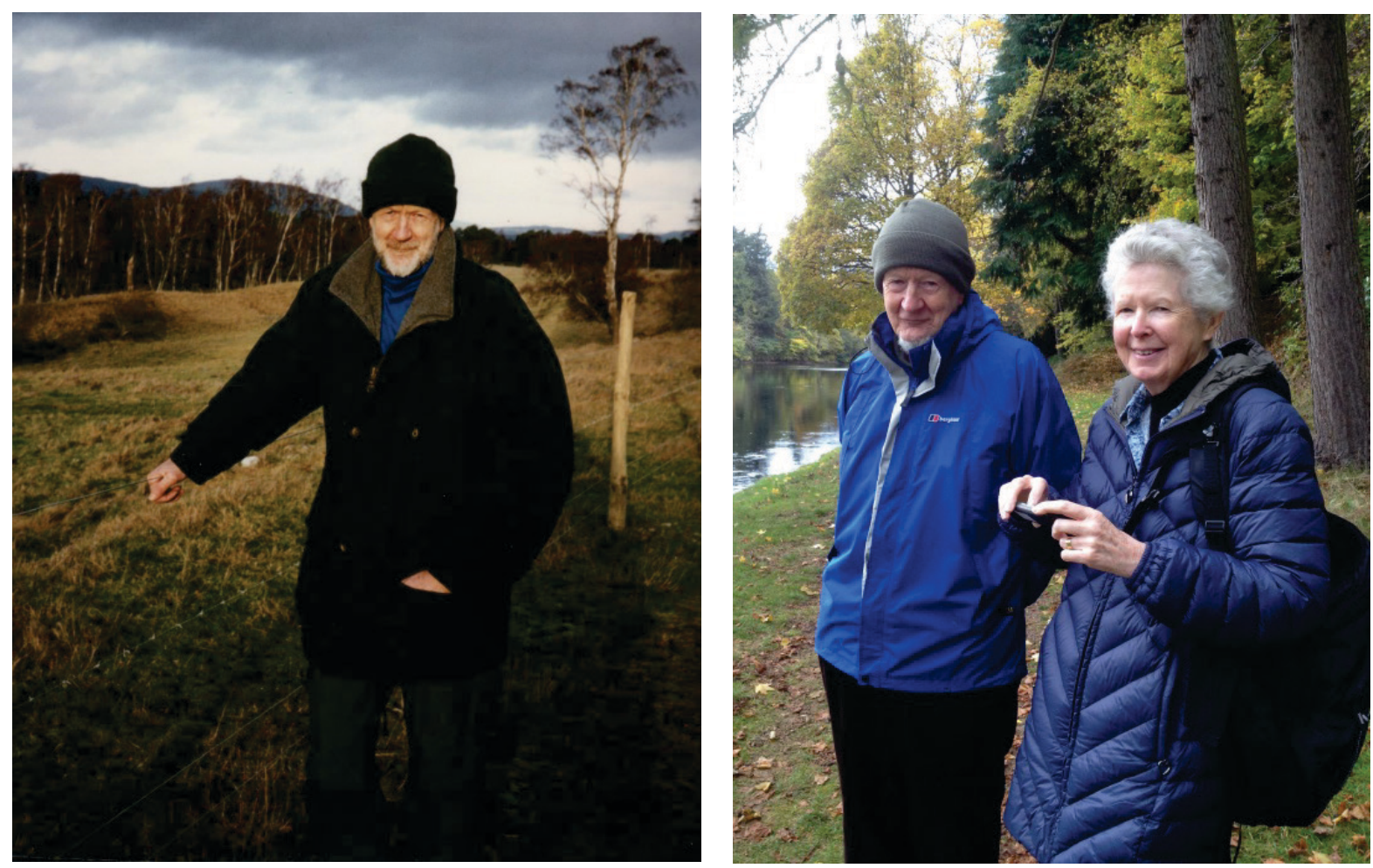

Figure 3. Left: Edward in 1997, during our visit to Pitlochry, right: Edward and Jean during one of their walks.

Edward enjoyed in good food and wine but the most he liked long walks and scientific talks, so I often discussed with him about my work. I appreciated his suggestions regarding research plans and occasionally
I asked him to read drafts of my papers and to give me his opinion about them. What to say at the end, Edward was real friend, not only of me but also of my family. 